\title{
ELEMENTOS DE HUMOR UNIVERSAL E HUMOR GALEGO NA FICCIÓN SERIADA. O CASO DE PRATOS COMBINADOS
}

\author{
Marta Pérez Pereiro \\ Universidade de Santiago de Compostela
}

Máis que a pena ou calquera outra emoción, George Bataille destacaba a risa como a forma máis lexítima de interacción humana. O humor ${ }^{1}$ tivo unha atención moi especial nos medios de comunicación de masas, seguindo a súa función (quizais única) de industria do entretemento. A televisión non foi unha excepción a esta produción de comicidade e, dende os seus inicios nos anos 50, podemos contar multitude de produtos en que o humor, contraposto aos programas «serios» como informativos, dramas seriados ou documentais, constitúe o elemento xerador de historias.

A televisión pode ser comparada co kolax (o adulador) grego, o bufón que, a cambio de comida, divertía os comensais nas festas privadas. Do mesmo xeito, os espectadores poderían denominarse ho trephon, os que dan alimento ao parasito televisivo que, ao contrario do que ocorría co bufón clásico, tamén pretende poñerse serio e facer chorar aos membros da audiencia. Non resulta, polo tanto, estraño que a televisión conteña o corpus narrativo de ficción máis grande da sociedade contemporánea.

En medio século de historia, o kolax electrónico tivo tempo de elaborar formas específicas para o humor na ficción. Pódese falar de varios formatos en que o humor é un elemento importante, pero é nas comedias de situación onde podemos afirmar que facer rir o espectador é case a única tarefa. Jaime Barroso define brevemente este formato de ficción:

1. Bremmer e Roodenburg definen o humor como «calquera mensaxe -sexa transmitida polo xesto, pola palabra, falada ou escrita, a imaxe ou a música- que pretenda provocar o sorriso ou risa». En: Bremmer, J. e Roodenburg, H. (coord.): Una historia cultural del humor, Madrid, Sequitur, 1999. 
a súa finalidade é o entretemento ("comedia amable»), aínda que non lle resulta allea a crítica ou a moralización social ao abordar historias de conflito relacional no seo da familia (unha mestura entre a comedia de costumes e a de carácter) e incluír situacións de actualidade. Os seus personaxes responden ao estereotipo da «xente corrente» e os conflitos xiran no contorno doméstico-laboral. A súa programación máis habitual responde á frecuencia semanal (Barroso, 1996:248).

Este formato é herdeiro directo da comedia teatral e do traballo dos showmen, maiormente radiofónicos, que monologaban nas ondas americanas. O mesmo que a meirande parte dos produtos televisivos, debemos as sitcoms á grande industria audiovisual dos Estados Unidos, pero o formato foi difundíndose por outras industrias locais nun proceso que Milly Buonanno denomina indixenización, pero que nós entendemos simplemente como un proceso lóxico de adaptación cultural. Trátase do proceso polo cal

formas e expresións de culturas externas, elaboradas por outras sociedades, son apropiadas, reelaboradas e restituídas por unha ou diversas sociedades locais en configuracións conformes e sintónicas co propio, autóctonos sistemas de significados, dando vida a formas e expresións que na súa natureza híbrida e sincrética, froito da mestura de ingredientes nativos e non nativos, aparecen recoñeciblemente marcadas por especificidades domésticas, e constitúen baixo cada perfil orixinais e auténticas creacións de cultura local (Buonanno, 1999:20).

Este proceso pode entenderse como un movemento de resistencia moderada ante a americanización dos contidos culturais e o lecer e, ao mesmo tempo, como unha estratexia de proximidade cultural, efectiva en canto que as audiencias televisivas confirmaron a rendibilidade da produción de iniciativas locais. No caso das sitcoms asistimos en España ao lanzamento dunha industria local, de certo éxito, inaugurada por produtos como Farmacia de guardia, unha serie que adaptou o formato americano a un escenario español no que se movían personaxes cunha graza máis próxima ao castizo que ao importado. 
Non obstante, non é o formato o elemento en que se fai necesaria unha adaptación cultural, senón o contido e, no caso que nos ocupa, no motor da idea da telecomedia, que é a intención de ofrecer ao espectador unha achega cómica a un conflito. Podemos contar con non poucos estudos sobre o humor, nunha vaga intención de definilo como un fenómeno puramente humano, moitos deles dende un punto de vista esencialista. Quizais un dos estudos máis en detalle sobre o cómico foi o de Henri Bergson, que, dende a metafísica, intentou desentrañar as claves do que activa o mecanismo da risa. Na actualidade, calquera tipo de investigación sobre o humorístico rexeita a idea do universal que Bergson, pretendera aplicar á súa análise, que, malia constituír un intento valioso, queda na descrición dunha serie de engrenaxes tanto físicas coma mentais sospeitosas de ser só aplicables a un tipo de sociedade, a occidental de principios do xx e, aínda así, queda suxeito a abundantes obxeccións propias de toda xeneralización teórica² ${ }^{2} \mathrm{Na}$ actualidade, autores como Peter Burke declaran a imposibilidade de estudos transculturais das fontes e manifestacións do cómico, ao mesmo tempo que emprenden proxectos limitados de xeito moi preciso en tempo e espazo.

O estudo do humor nunha tecnoloxía como a televisión non é alleo a esta necesidade de delimitación, por moito que existan ficcións que triúnfan máis aló das fronteiras da cultura que as crea. O xeito de narrar elixido, a linguaxe empregada para provocar a risa ou a recepción que a audiencia ten do produto non son extensibles a todo sistema cultural. Neste marco, propoñémonos achegarnos ao humor que, aproveitando un formato internacional, como é a comedia de situación, se propón na ficción galega, aproveitando, como material de estudo, a serie Pratos combinados, unha das series pioneiras deste xénero.

Pratos combinados comezou a emitirse en decembro de 1995 e, de xeito case ininterrompido, permanece na programación

2. Temos que dicir que, de todos os xeitos, resultan útiles os mecanismos que describe Bergson porque son os básicos dos exemplos que dá: teatro, cine e literatura, que están na base de toda produción cultural europea da actualidade. 
da Televisión de Galicia ata o ano 2006 como unha das principais captacións de audiencia ${ }^{3}$. Trátase, polo tanto, da teleserie máis veterana do Estado, xa que se mantén en antena despois de sete anos de emisión, algo a todas luces sorprendente, se o comparamos co imparable baile de programas ao que asistimos nos nosos televisores ${ }^{4}$. Postulamos a hipótese de que é precisamente a adaptación cultural da comedia de situación ao ámbito galego a responsable do éxito da serie e, máis en concreto, o uso dun humor autóctono -o que Javier Maqua denomina ironicamente como «endogargallada»-, que reafirma o propio (mesmo ridiculizándoo). A este respecto, indica Fritz Graf que «en xeral, o propósito do humor étnico non consiste en censurar, en corrixir, senón en afirmar, por mor da diferenciación, a propia identidade (in Burke et al., 1999:34)».

Precisamos dunha definición do que puidera ser o «humor galego» pero, o mesmo que ocorría cos intentos filosóficos de determinar a orixe da risa en todos os humanos, como nunha caste de risa universal, córrese o risco de caer en explicacións de carácter esencialista, que non nos serven para o propósito de definir a risa como un fenómeno cultural diferenciado. Prescindimos, polo tanto, de intentos de pensadores como Celestino Fernández de la Vega, quen sostén que o humor galego, pola súa raíz celta, é o único digno de ser tido en conta como tal. O resto de manifestacións serían cómicas ou satíricas- no marco do Estado, negándolles esta capacidade, deste xeito, a valencianos ou andaluces. Ao fío

3. Podemos tomar como exemplo que ilustra esta afirmación o índica de audiencia que a serie obtivo na temporada 2002/03. Pratos combinados converteuse no programa máis visto da TVG, cun share do $262 \%$, case dez puntos por riba da media da canle.

4. Con todo, convén indicar que a programación da TVG, cunha historia relativamente breve, é eminentemente estable; adoitan conservarse aqueles programas que supoñen un éxito de audiencia e, no caso das series, sexan do xénero que sexan, é frecuente que a súa duración se aproxime perigosamente á case interminable telenovela, no caso das series con tramas de continuidade, algo que non ocorre no caso que nos ocupa. A propia Pratos combinados ou a máis recente Mareas vivas son exemplos desta política de programación. Por outra banda, a continuidade das series de ficción nas que se aprecia éxito, medido nos niveis de audiencia correspondentes, provén do importante investimento económico que nelas teñen que facer produtoras e canles de televisión. 
destas consideracións, malia que atenuadas, atopamos o discurso de ingreso na Real Academia Española de Wenceslao Fernández Flórez, baixo o título «El humor en la literatura española», no que se afirma que Galicia é «a rexión onde xorden máis escritores humoristas» (Fernández Flórez, 1945:41) e fala da orixe galega de Cervantes como factor decisivo á hora de consideralo o grande autor de humor da literatura española.

Tomaremos da antropoloxía unha argumentación breve do que pode ser o sistema de pensamento galego, orixe do seu sentido do humor: "particular forma de pensar que se dá na cultura galega e que consiste en enfocar os problemas de xeito non excluínte senón complementario»(Gondar Portasany, 1993:45). Esta ambivalencia ${ }^{5}$, indica o mesmo autor, fai que o galego pense «en círculos discéntricos ou, quizais mellor, policentrados» (Gondar Portasany, 1993:57). Este xeito de pensar constitúe a orixe da retranca, a fórmula máis habitual que define o humor galego, entendido polos propios, considerado mesmo unha virtude, un exercicio de habilidade social, no xeito de vida tradicional, pero cualificado como indecisión, ou ata malicia, polos estraños. (Non resulta, polo tanto, difícil de entender que non existan análises do humor galego por parte de non galegos). Non obstante, non podemos considerar a ironía como un patrimonio galaico, senón como unha forma de resistencia que comparten as culturas sobre as que pesa, dun xeito ou outro, a hexemonía dun sistema cultural externo. Antoine de Baecque, a este respecto, sostén que «a risa adquire maior relevo cando choca coas fontes da cultura oficial; cando non procede en absoluto rir» (in Burke et al., 1999:180); de aí tamén a importancia do que Aaron Gurevich considera «esvaramentos» do humor, como poden ser os compoñentes escatolóxicos ou irreverentes, que dan mostra da elasticidade de certas culturas no seu modo de percibir o contorno. O interese do galego por evi-

5. Gondar Portasany ilustra esta afirmación por medio de numerosas expresións populares estendidas como tópicos máis aló das fronteiras de Galicia (expresións moi coñecidas como a que sitúa o galego no medio dunha escaleira sen saber se sobe ou baixa) e por medio da descrición do sistema de crenzas galego, no que Deus é bo, pero o demo non ten necesariamente porque ser malo. 
tar a resposta directa, por informar ao seu interlocutor de certos datos que prefire obviar, deriva neste tipo de humor que rexeita respostas concluíntes.

Veremos agora como estes intentos de definir o humor galego funcionan no noso obxecto de estudo, a serie Pratos combinados. Poderiamos considerar no produto audiovisual, para comezar a nosa argumentación -como fixeramos co marco deste traballo-, buscar que queda do orixinal americano, aspirante a universal nos medios de comunicación ${ }^{6}$. A súa forma responde perfectamente ao modelo de sitcom, con episodios en que o conflito acaba por resolverse; nun contorno laboral-familiar ${ }^{7}$ (toda a acción transcorre no Bar Suízo e no domicilio da familia Pereira, propietaria así mesmo do establecemento) e con personaxes fixos, que reaccionan seguindo os mesmos patróns ao longo de toda a ficción.

Deterémonos un pouco máis nos conflitos creados e nos personaxes da serie. As tramas propostas poderían ser transportables a calquera outra ficción do Estado, sen que os espectadores tivesen ningún problema de comprensión. Xosé Cermeño ${ }^{8}$ explica que

a serie xoga con elementos da realidade e da actualidade, mesturando elementos recoñecibles, tópicos, recreacións, deformacións [...] máis ca unha identidade colectiva o que reflicte a serie é a convi-

6. Nos últimos anos de emisión, Pratos combinados sufriu algunhas modificacións que o afastan do modelo máis estrito de telecomedia: rodaxe en exteriores, ampliación de espazos onde se desenvolven os conflitos e ampliación da emisión de 25’ a 55'. Todos estes cambios teñen que ver sobre todo co incremento dos orzamentos para a serie, que permiten maiores alardes técnicos que redundan na narración, nun intento de ofrecer á audiencia «máis do mesmo», xa que o tipo de historia e os seus personaxes centrais apenas se transformaron. O éxito das series españolas como Médico de familia influíu na transformación de certas series en dramedias, ficcións de maior duración nas que se combinan comedia e drama.

7. Pode ser interesante notar que o modelo social americano fai que as relacións laborais deveñan en familiares, mentres que no caso galego acontece todo o contrario: son as familias as que desenvolven negocios xuntas, ben por herdanza de negocios, ben por asociación dos esforzos de varios membros do núcleo familiar, sexa este o da casa ou se estenda a parentes máis ou menos afastados.

8. Os datos que incorporamos ao texto obtivéronse nunha entrevista mantida con Xosé Cermeño, creador da idea e un dos guionistas da serie, en xaneiro de 2002. 
vencia de personaxes que responden a distintas actitudes xeracionais, profesionais, sociais...

Os tipos de conflitos en que se enlean os personaxes teñen, por todo isto, moito que ver cos argumentos clásicos da ficción literaria, que foron trasladados e adaptados aos medios audiovisuais.

En canto á descrición dos protagonistas, atopamos nas súas caracterizacións os ingredientes que funcionaron probadamente na produción de ficcións seriadas. O núcleo é familiar: un pai, Miro Pereira, o personaxe central da serie; a súa muller, Balbina; a sogra desta, dona Carme; o cuñado de Miro, Antón; e os dous fillos do matrimonio. Ao seu redor xiran personaxes relacionados coa vida do contorno profesional do bar, clientes e outros comerciantes da rúa, e os veciños do barrio onde se sitúa o Bar Suízo. A meirande parte dos conflitos que se desenvolven na narración teñen que ver co carácter de Pereira. Segundo o seu propio creador é «un home como hai moitos: un marido inútil e un profesional torpe, permanentemente desconcertado por un mundo que non entende.» Definición á que poderiamos engadir cualificativos como preguiceiro, pouco xeneroso e estafador amateur. Bergson dixera ao respecto de personaxes en que domina un vicio ou unha torpeza de carácter, que é precisamente o descoñecemento desta faceta da súa personalidade o que lle confire comicidade. Miro Pereira parece inocente respecto de actos tales como «facer café sen café»-unha das frases recorrentes da ficción-, o que impide a posibilidade de emenda. Atopamos personaxes con certas concomitancias no imaxinario europeo, como o obreiro alemán coñecido xenericamente como Nante Eckennteher, figura importante no humor gráfico do século XIX, caracterizado pola súa preguiza e inutilidade, e representado na súa eterna posición apoiado nunha esquina da rúa9.

9. É interesante tamén comprobar como estes personaxes xorden nos medios de comunicación de masas destinados á poboación obreira no século XIX e son incluídos en produtos televisivos de alto consumo na actualidade. O modelo do personaxe diverxente, no sentido do que se espera da clase traballadora, é un recurso cómico moi empregado, ao xeito dos personaxes «inferiores» na comedia teatral. 
A relación entre Miro Pereira e Antón é a orixe principal dos conflitos. Ambos os dous son lacazáns e comparten soños de enriquecemento, o que os leva a enlearse en proxectos que sempre saen mal, ben sexa pola torpeza de Miro, ben polo exceso de astucia de Antón, que complica os asuntos de máis sinxela resolución. O resto dos personaxes, aínda que teñen ás veces o seu protagonismo, intentan resistir do mellor xeito posible as continuas inestabilidades que provoca a asociación funesta deste dúo cómico.

Con todo o visto ata aquí poderiamos estar falando de produtos como Manos a la obra, serie emitida por Antena 3, na que funciona unha parella de protagonistas de características similares, ou sen saírmos da propia televisión galega, o dúo dos Tonechos ${ }^{10}$, que ten un modelo de tramas, presentación e resolución de conflitos moi semellante ao da alianza Miro-Antón. Recoñecemos baixo esta aparencia primeira unha serie de trazos que teñen que ver coa cultura galega, por unha parte en canto ao contexto e caracterizacións dos personaxes e, por outra, con referencia ao humor que reflicten os guións e o uso da lingua.

En primeiro lugar, habería que falar da situación social dos personaxes principais, que representa un modo de vida habitual nas vilas galegas. O Bar Suízo é un negocio frecuente; ademais de que a cantidade de bares por habitante en Galicia excede con moito a media do Estado, constitúe unha opción para os emigrantes retornados. Neste caso, a familia Pereira pode contar unha experiencia que foi fundamental na vida de moitos galegos: despois de varios anos de traballo en Suíza - de aí o nome do bar- o

10. Rodríguez, Salvador: «El boom de Os Tonechos», «Estela», Faro de Vigo, 22 de febreiro de 2004, pp. 1-4, ano 3, n. ${ }^{\circ}$ 95. «Pienso que la clave de nuestro éxito -reflexiona Víctor- es que todos los elementos con los que trabajamos existen, forman parte de la realidad, así que el que más y el que menos conoce a alguien que habla de esa manera o le pasa eso que contamos. Nosotros nos fijamos en detalles y los llevamos a escena, a veces con una apariencia surrealista, sí, pero si hay una palabra clave en todo lo que hacemos, esa es identificación», Víctor Fábregas (Tucho). Gayoso: «Lo que pasa es que los sketches que preparan tienen como destino al público gallego, que es el público de Luar. Pero una cosa son estos personajes, con su forma de hablar, con sus giros y con sus expresiones enxebres, y otra distinta los actores que los encarnan. Tal vez Os Tonechos no triunfen fuera de Galicia, pero Víctor y Roberto sí (...)». 
retorno ao país de orixe implica a necesidade dun medio de vida no que investir todo o aforrado no estranxeiro e, ao mesmo tempo, unha mentalidade relacionada co vivido. Neste caso, Miro Pereira ten un especial interese pola ganancia económica ou, mellor, polo aforro, sen dúbida unha rémora da súa experiencia de privacións en Europa. Esta circunstancia compleméntase coa orixe de Miro, un ourensán de Ribadavia, polo tanto, nos tópicos creados polos galegos para definirse entre si, un personaxe cun punto máis ao seu favor na condición de mísero. Estes códigos, perfectamente recoñecibles polo espectador galego, non resultan tan evidentes para unha posible audiencia foránea, que non conta na súa bagaxe histórica coa experiencia da emigración masiva nin manexa tópicos do lugar.

O resto dos personaxes das tramas poderían perfectamente ser «cidadáns do mundo», posto que son profesionais que rexentan os seus negocios e viven condicionados polas andanzas de Miro e Antón e mais dos seus fillos xa que, nas series de corte familiar, os cativos contan co seu particular conxunto de trama, normalmente de enredo.

Atopamos, con todo, unha marca especialmente clara do humor galego en Pratos combinados no tipo de respostas que se ofrecen aos conflitos, máis universais, que se presentan en cada capítulo. Todos os personaxes empregan entre si as armas de astucia que comentabamos en liñas superiores. A ironía é unha das respostas fundamentais dadas aos problemas presentados, de xeito que cando Balbina insta a Miro Pereira a traballar, co engadido de que «o traballo é saúde», o dono do Suízo decide que é xeneroso ao poder brindar esa oportunidade aos enfermos. O dobre sentido, a sorna e a retranca son os elementos cómicos fundamentais da serie, de xeito que o fluír da acción vén determinado polas respostas que os personaxes lles dan ás dificultades diarias, en especial aos problemas creados polo dúo xerador de accións Miro-Antón. Trátase de diálogos breves, que teñen moito que ver coas viñetas de prensa pola súa concisión. O propio creador do produto, Xosé Cermeño, manifesta que o humor gráfico é unha das influencias do 
seu traballo ${ }^{11}$ xa que nelas hai unha gran cantidade de información exposta de maneira breve, algo imprescindible para unha serie de televisión na que o espectador demanda ritmo nas escenas.

As formas humorísticas «esvaradas», como denominaba Gurevich ao obsceno, escatolóxico e irreverente, tamén están presentes na narrativa de Pratos combinados, de xeito que se pon de manifesto unha das desviacións clásicas do sentido do humor galego: o relativismo co que se enfronta a vida aplícase do mesmo xeito á morte, relativismo que, combinado coa superstición, derivan nun humor negro manifesto na ficción galega e na súa tradición oral ${ }^{12}$.

Malia a ironía que manexan con destreza todos os personaxes e que empregan no seu propio beneficio, ben para gañar tempo, ben para confundir ao contrario, botamos en falta un tipo de humor que tamén funciona con certa frecuencia nas ficcións televisivas: a sátira. Neste caso, entendemos que a crítica máis aceda do social e dos costumes se dulcifica pola necesidade de crear un «humor branco», que permita unha lectura atemporal das tramas, xa que evita as alusións a situacións da vida real. Por outra parte, respecta a política de programación da TVG, caracterizada pola ausencia de sátira (resultaría imposible ver unha serie galega emitida pola canle autonómica na que se vira algún tipo de alusión ao momento político. Resulta, polo tanto, chocante que nun bar como escenario principal non se faga alusión ningunha a temas deste tipo, por superficial que sexa).

O escritor e humorista gráfico Castelao cualificou o galego como un hipercrítico, actitude ante a vida que casa perfectamente coa desconfianza cómica que teñen entre si os personaxes de Pratos

11. Podemos citar varios humoristas gráficos galegos que supuxeron unha grande influencia, non só para o caso que nos ocupa, senón tamén para todas as manifestacións realizadas en Galicia, Álvaro Cebreiro, Carlos Maside ou Castelao.

12. A este respecto o humorista Siro López comenta que é fácil atopar abundantes mostras de humor macabro nas narracións sobre o tránsito entre a vida e a morte en Galicia. Acotío, os contos sobre a Santa Compaña son moi complexos, xa que neles aparecen multitude de personaxes que, en conxunto, conforman unha escena certamente cómica. Outro bo exemplo de humor «deslizado» na ficción galega son os relatos breves de Ánxel Fole, recolleitos da tradición oral. 
combinados, afeitos a enfrontar os problemas económicos, emocionais, laborais... con relativismo e tomando, con moita frecuencia, frases da sabedoría popular para ilustrar as devanditas actitudes. $\mathrm{O}$ uso da lingua galega, ademais de garantir a proximidade cultural á audiencia, é un importante catalizador do humor, de xeito que se toma boa parte da fraseoloxía popular e dos insultos máis cómicos para potenciar o efecto humorístico dos guións. Descualificacións, inxurias e alcumes son elementos esenciais para a gargallada en Pratos combinados, o mesmo que os xuramentos, como o que terminou por definir a Miro Pereira para o conxunto da audiencia, «Cagho no mundo!».

Por todo o visto podemos concluír que Pratos combinados parte dun modelo habitual na ficción televisiva que podemos ver nestes momentos no Estado, unha vez iniciada unha produción a grande escala de serie, pero que, partindo de historias certamente recoñecibles e estandarizadas, acaba por acadar un produto en que as manifestacións do humor galego, en forma de retranca e ironía, son esenciais. Nada mellor para concluír que o exemplo que Xosé Cermeño emprega para definir o humor que manexa a serie: «a ironía, a crueldade e a capacidade crítica do noso humor están perfectamente sintetizadas na famosa viñeta de Castelao, na que unha rapaza lle dicía ao seu mozo, "se fora rica quereríasme máis" e el contestaba, "non tería por que quererte menos"». 


\section{REFERENCIAS BIBLIOGRÁFICAS}

Barroso García, J.: Realización de los géneros televisivos, Ed. Síntesis, Madrid, 1996.

Bergson, H.: Introducción a la metafísica; La risa, Porrúa, México, D.F., 1999.

Buonanno, M.: El drama televisivo: identidad y contenidos sociales, Gedisa, Barcelona, 1999.

Fernández FlóRez, W.: El humor en la literatura española. Discurso de ingreso en la Real Academia Española, 1945.

Fernández de la Vega, C.: O segredo do humor, Galaxia, Vigo, 1963.

Gondar Portasany, M.: Crítica de la razón gallega, A Nosa Terra, Vigo, 1993.

LóPEz, S.: «Humor e identidade en Galicia», en Galicia fai dous mil anos. O Feito Diferencial Galego na Antropoloxía, vol. II, p. 37-49, Museo do Pobo Galego, Santiago de Compostela, 1999.

MAqUA, J.: «Sobre las risas enlatadas en las telecomedias españolas», Archivos de la Filmoteca, n. ${ }^{\circ}$ 19, Valencia, 1995.

Rodríguez, S.: «El boom de Os Tonechos», «Estela», Faro de Vigo, 22 de febreiro de 2004 (ano 3), n. ${ }^{\circ}$ 95, p. 1-4.

Villagrasa, J. M.: «El género televisivo de las telecomedias», Archivos de la Filmoteca, n. ${ }^{\circ}$ 19, Valencia, 1995.

VV.AA.: El anuario de la televisión, Geca, Madrid, 2004.

VV.AA.: Historia cultural del humor: desde la antigüedad a nuestros días, Sequitur, Madrid, 1999. 